\title{
Value of Pelvic Magnetic Resonance Imaging in Local Staging of Rectal Cancer
}

\author{
MOUSTAFA E. RADWAN, M.D. ${ }^{\mathbf{1}}, \mathbf{2}$; EHAB M. ABDELRAHEEM, M.D. ${ }^{\mathbf{3}}$; \\ ABD EL KARIM ABD ALLAH, M.D. ${ }^{\mathbf{1}}$; AFAF HASAN, M.D. ${ }^{\mathbf{1}}$; MOHAMMAD EL OSSEILY, M.D. ${ }^{\mathbf{4}}$ and \\ EHAB MOUSA, M.D. ${ }^{1}$ \\ The Department of Radiodiagnosis, Faculties of Medicine, Assiut University, Egypt ${ }^{1}$ and Taibah University, Saudia Arabia ${ }^{2}$, \\ The Department of Tropical Medicine, Faculty of Medicine, Minia University ${ }^{3}$ and The Department of Surgery, \\ Faculty of Medicine, Assiut University ${ }^{4}$, Egypt
}

\begin{abstract}
Background: The prognosis for patients with rectal cancer is closely related to the stage of the disease at the time of diagnosis. Currently, rectal Magnetic Resonance Imaging (MRI) is the most encouraging imaging modality for local staging of rectal cancer.
\end{abstract}

Aim of Sudy: This study aimed to evaluate the role of pelvic MRI in staging of the rectal cancer for management decision.

Patients and Methods: This prospective study included 30 patients who proved to have rectal cancer by clinical and histopathological studies. Pelvic MRI was accomplished for all patients according to the following protocol: Sagittal T2WI; Axial T2WI; Axial T 1 SPIR; Axial T 1 WI; and Coronal T2 TSE. T staging and $\mathrm{N}$ staging were performed for the lesions.

Results: Thirty patients were included in this study, 21 males and 9 females with their ages range between 19 and 80 years (mean $=43$ years). MRI defined the location of the tumor in the upper third ( 2 cases), 6 cases at the middle third and in 21 cases at the lower third of the rectum. T staging: No lesions were staged as $\mathrm{T} 1$, one case was staged as T2, twentythree lesions were diagnosed as T3; five cases were diagnosed to have $\mathrm{T} 4$ lesion (local infiltration) involving; prostate (4 cases) and infiltrating the skin and penile root in another case. The operative findings confirmed MRI data in those cases. One case was staged as T0 stage following proctoscopic resection of rectal polyp and proved to be rectal carcinoma (villous carcinoma). The sensitivity of MRI was identical to (100\%) operative and histopathological assessment in all T stages from ( $\mathrm{T} 1$ to $\mathrm{T} 4)$. $\mathrm{N}$ staging: The $\mathrm{N}$ stage was interpreted according to the TNM classification, any enlarged node in this study was suspected to be positive for metastatic deposits.

Conclusions: Pelvic MRI provides high resolution images of the entire mesorectum allowing for an accurate staging of rectal cancer. It offers multiplannar capabilities with high resolution, non-invasive however it is relatively a costly examination. It is of high value in building up the best therapy strategy for cancer rectum patients.

Correspondence to: Dr. Moustafa E. Radwan, E-Mail: ezeldienmos@yahoo.com
Key Words: Cancer rectum - Pelvic MRI - Local staging.

\section{Introduction}

RECTAL cancer is viewed as the second most common malignancy in the western world. In the United States, it addresses the third leading cause of new cancer cases and cancer-related deaths in both men and women [1]. In the European Union countries, colorectal cancer causes more than 110,000 deaths per year. The occurrence of colorectal cancer increased after the age of 47 years, showing up at a biggest at around 65 years. The commonness is impressively higher in more developed countries than in less developed countries. However, the death rate in more developed countries is lower, reflecting expanded screening and improvements in rectal cancer staging and therapy [2]. The prognosis for patients with rectal cancer is closely related to the stage of the disease at the time of diagnosis and the decision of therapy. The risk of post-operative tumor recurrence is $5 \%$ for stage T1, $10 \%$ for stage $\mathrm{T} 2$, and $25 \%$ for stage T3, utilizing the TNM staging system. In case of lymph node involvement, the risk of tumor recurrence increases to $33 \%$ for a stage T2 tumor and $66 \%$ for stage $\mathrm{T} 3$ [3].

Currently, rectal Magnetic Resonance Imaging (MRI) is the most encouraging imaging modality for local staging of rectal cancer [4]. MR imaging utilizing a transrectal coil has been shown to be effective in revealing the layers of the rectal wall, which is an essential for accurate staging [5]. However, MR utilizing a transrectal coil has similar constraints as transrectal sonography with respect to the field of view and the assessment of stenotic tumors. The identification of tumors close to or 
invading the mesorectal fascia has gotten progressively significant, may be impressively more significant than the classic $\mathrm{T}$ stage determination [6]

Rectal MRI may add extraordinary value in essential staging (preoperative setting), MRI can aid in (1) Choosing patients with locally advanced rectal cancers who are suitable for treatment with Neoadjuvant chemoradiotherapy; (2) Distinguishing poor prognostic factors, including extramural vascular invasion and involvement of the mesorectal fascia (3) Directing surgeons in surgical planning [7]. The potential advantages accomplished with rectal MRI are carefully reliant on getting great quality images to allow for characterization of the main anatomic structures and their relation to the tumor. High-spatial-resolution T2-weighted imaging (T2WI) is the most important MRI sequence in the assessment of rectal cancer and anatomic structures [8]

Aim of the work:

This study aimed to assess the role of pelvic MRI in evaluation and staging of the rectal cancer and the impact of this evaluation upon the plan of treatment, with emphasis on comparing the results with the operative and post-operative histopathological findings.

\section{Patients and Methods}

\section{Patients:}

This prospective study was conducted during the time frame from July 2018 to November 2020. The study included 30 patients: 21 males and 9 females with their ages range between 19 and 80 years with mean age $43 \pm 3.8$ years. Patients were referred from Tropical Medicine Department; Minia University and Surgical Department; Assiut University to Radiology Department, Assiut University for pelvic MRI.

Inclusion criteria: Patients who proved to have rectal cancer by clinical and histopathological studies.

Exclusion criteria: Patients who proved to have distant metastases, patients refusing operative treatment and patients proved to be inoperable. This study was approved by the Review Board of the institution and informed consent was attained from all patients prior to scanning.

\section{Methods:}

The diagnosis of rectal cancer in these patients was established dependent on their symptomatology, clinical examination, proctoscopy, and biopsy.
Pelvic MRI was done for all patients; abdominal ultrasonography and chest X-ray were also done to all patients to exclude distant metastases. CT pelvi-abdomen was accomplished for 12 patients, while barium enema was done for 3 patients; the results of these investigations were audited cautiously before including the patients into the study population, to acquire an initial idea about the lesion and to confirm the absence of distant metastases.

Routine laboratory evaluation including complete blood picture, liver function tests, renal function tests and prothrombin time and concentration were also performed.

1- Clinical evaluation: Patients were subjected to full clinical assessment including analysis of the history and complaints, symptoms duration. Rectal bleeding and recent changes in bowel habits were of special concern. General, abdominal, and local digital rectal examination were done.

\section{Symptomatology:}

All patients (100\%) presented by bleeding per rectum of varying degrees, in addition to bleeding; 5 patients $(16.7 \%)$ presented by diarrhea, 4 patients (13.3\%) presented by constipation, and one patient $(3.33 \%)$ had sense of mass or inadequate evacuation. Laboratory evaluation revealed mild to moderate hypochomic microcytic anemia in 5 patients (16.7\%); 4 males and 1 female. Proctoscopic examination showed malignant featuring rectal lesions at variable distance from the anal verge. Most of the lesions were in lower and middle third and biopsies were taken for histopathologic evaluation.

2- Proctoscopic examination: Light sedation after preparation for endoscopic evaluation of the lesion and biopsies were taken and sent for histopathologic evaluation.

3- Abdominal and pelvic Ultrasound examination.

4- Magnetic Resonance Imaging: All patients were examined using $1.5 \mathrm{~T}$ superconductive scanner (Philips Gyroscan ACS-NT) equipped with received only phased array torso coil, which consists of two coupled coils placed anterior and posterior to the pelvis and fixed with straps.

\section{Patient preparation:}

The patients were given a light cleansing enema the night before examination to clarify the rectal lumen. At the beginning of examination 150c.c. normal saline were installed in the rectum via a non-inflated Foley's catheter to delineate the rectal 
lumen and the patients could withhold this during the examination time.

\section{Technique of examination:}

The patients were examined in supine position with the fixed piece of the coil underneath; at the region of the pelvis and buttocks and the second piece of the coil was placed over the pelvis and perineum. Following an initial multi-planar localizer; Sagittal, Axial and Coronal sections were obtained in different pulse sequences according to the following protocol: Sagittal T2WI; (TSE, TR 3500, TE 90, FOV 280/1.7, Matrix 198 X 256, NSA 2, THK/GP 4/1). Axial T2WI; (TSE, TR 3984, TE 150, FOV 320/3.5, Matrix 198 X 512, NSA 3, THK/GP 3/0). Axial T1SPIR; (TR 49, TE 4.6, FOV 290/2, Matrix 256 X 256, NSA 1, THK/GP 5/1). Axial T1WI; (TR 550, TE 14, FOV 310/1.1, Matrix 231 X 512, NSA 3, THK/GP 4/1). Coronal T2 TSE; (TR 3500, TE 90, FOV 250/1.7, Matrix 199 X 256, NSA 3, THK/GP 4/1). No respiratory triggering, sedation or anesthesia was required in the examined cases.

\section{Image analysis:}

The detected lesions in MRI were described regarding, site, size, signal intensity and extent of infiltration into the ano-rectal wall, extension into the perirectal fat and adjacent structures. Presence of local or regional lymph node enlargement was also documented.

At first the site of the lesion was documented, measuring the distance between the lower border of the lesion and the anal verge. According to this, the lesion was located as upper third $(12-16 \mathrm{~cm})$, middle third $(8-11 \mathrm{~cm})$ and lower third $(4-7 \mathrm{~cm})$ or anorectal in position.

The shape of the lesion regarding is it circumferential, involving one side or other appearance was described. The signal intensity of the lesion in T1WI, T2WI and SPIR WIs were described in detail.

Staging was performed, in accordance with the TNM system by Kumar [9].

T staging was performed: when the rectal mass (usually hypersignal in T2WI), invaded the submucosa, the lesion was staged as T1. T2 was applied when the mass was seen infiltrating the muscularis propria and not breach through the later. T3 was applied when the lesion infiltrated the muscularis propria and extending to the perirectal fat without adjacent organ infiltration. T4 was applied when there was infiltration of an adjacent organ.
$N$ staging then was performed: The perirectal LN were seen scattered at the mesorectum and best seen in transverse images. They could be seen in T1WI and T2WI with usually hypo, hyper-signal, respectively. N0 was applied when there was no detectable LN enlargement. N1 was applied when there were one to three enlarged perirectal LNs. $\mathrm{N} 2$ when there were 4 or more enlarged perirectal LNs and N3 when there was any enlarged LN along a named vascular trunk. The number and size of the enlarged nodes were described, the site was described according to perirectal position like the clock, and signal intensity of the enlarged nodes is documented.

The interpretation of the results was based upon the invasion of the five layers of the bowel seen in MRI and staged based upon the TNM staging system. Correlation with the results of surgical operation and post-operative histopathological findings were performed.

\section{Statistical analysis:}

Data were analyzed using IBM SPSS software (release 25) (Windows Microsoft; SPSS Inc., USA). Statistical methods included descriptive analysis, such as mean $\pm \mathrm{SD}$, percentage, and frequencies.

\section{Results}

Thirty patients were included in this study, 21 males and 9 females with their ages range between 19 and 80 years with mean age $43 \pm 3.8$ years.

\section{MRI Location of the tumor:}

The lesion located in two cases at the upper third, in 6 cases at the middle third and in 21 cases at the lower third of the rectum (Table 1).

Table (1): Distribution of tumors by anatomical location in MRI examination.

\begin{tabular}{lcl}
\hline Tumor location & $\begin{array}{c}\text { No. of } \\
\text { cases }\end{array}$ & Percentage \\
\hline Upper third (12-16cm from anal verge) & 2 & $6.67 \%$ \\
Middle third (8-11 cm from anal verge) & 6 & $20 \%$ \\
Lower third (4-7cm from anal verge) & 21 & $70 \%$ \\
Undetected tumors & 1 & $3.33 \%$ \\
\hline Total & 30 & $100 \%$ \\
\hline
\end{tabular}

\section{Characterization of the lesions:}

In all cases tumors showed higher signal intensity (SI) in contrast to the hypointense muscle layers in T2WI. In three of them the masses showed higher SI than other detected masses and were proved to be mucinous carcinomas by the postoperative histopathological study. All cases showed 
iso to hypointense signal in T $1 \mathrm{WI}$. In two cases where IV Gadolinium (Gd) was administered, the tumors showed mild homogeneous enhancement. Two cases showed cystic changes of the adjacent healthy wall of the rectum as well as within the masses, those patients were complaining of long history of piles. No signal void or calcifications were detected in the studied cases.

\section{Staging:}

MRI staging:

\section{T stage:}

No lesions were staged as T1 by MRI i.e., no lesions were confined to the mucosal layer of the rectal wall. In one case MRI showed invasion of the rectal layers up to the muscularis propria with no infiltration of the muscularis propria or perirectal fat planes and was staged as T2 stage, histopathological findings were concordant with the MRI findings in this case. Twenty-three lesions were diagnosed as $\mathrm{T} 3$; in these cases, there were invasion of all rectal layers with perirectal fat infiltration, yet without extension into adjacent organs. This was confirmed by operative and histopathological

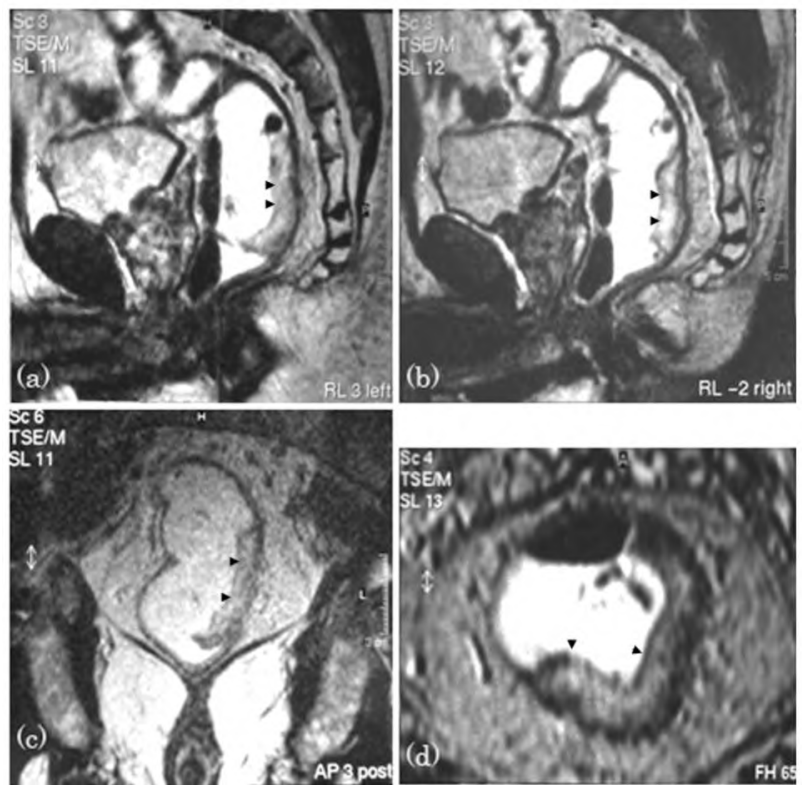

Fig. (1): A-60-year male patient, presented by bleeding per rectum and deep pelvic pain. Pelvic MRI: Sagittal T2WI (A \& B), Coronal T2WI (C), Axial T2WI (D) showed left lateral and posterior rectal wall thickening $7 \mathrm{~cm}$ from the anal verge extending for $5.5 \mathrm{~cm}$, infiltrating the mucosal and submucosal layers reaching the muscularis propria yet with no signs of breaching, the lesion is slightly hyperintense in T2WI, extending into the lumen with shouldering. Clear perirectal fat planes, no pelvic organs infiltration, no regional Iymphadenopathy. MRI staging: T2 N0 M0, anterior pelvic resection was done with post-operative pathological staging of T2 N0 M0. Pathological diagnosis; rectal carcinoma "Mucinouscarcinoma grade II". examination (100\% accuracy). Five cases were diagnosed to have T4 lesion (local infiltration) involving; prostate (4 cases) and infiltrating the skin and penile root in another case. The operative findings confirmed MRI data. In one case in which a rectal polyp was excised and proved to be rectal carcinoma (villous carcinoma), MRI was done following the proctoscopic resection for assessment of rectal wall and showed no residual masses or other lesions and this was proved in operative resection and post-operative histopathological study (Table 2) and Figs. (1-3).

Table (2): Correlation between MRI and operative and histopathology in tumor penetration in rectal wall.

\begin{tabular}{llcl}
\hline Stage & MRI & Operative & Histopathology \\
\hline T0 & 1 & 1 & 1 \\
T1 & 0 & 0 & 0 \\
T2 & 1 & 1 & 1 \\
T3 & 23 & 23 & 23 \\
T4 & 5 & 5 & 5 \\
\hline Total & 30 & 30 & 30 \\
\hline
\end{tabular}
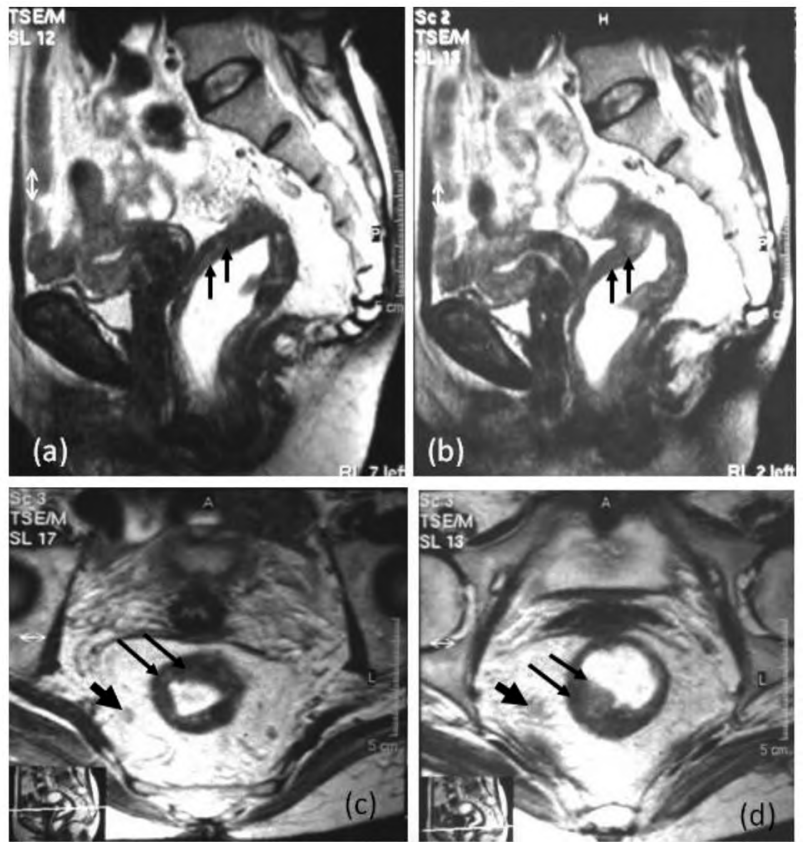

Fig. (2): A-51-year female patient, presented by bleeding per rectum and pelvic pain. Pelvic MRI: Sagittal T2WI (A \& B), Axial T2WI (C \& D) showed circumferential rectal wall thickening $8 \mathrm{~cm}$ from the anal verge extending for $5 \mathrm{~cm}$, infiltrating all rectal layers with minimal extension into the perirectal fat. The lesion is iso to hypointense in T2WI, extending into the lumen with minimal encroachment and narrowing. No pelvic organs infiltration. Few (less than three) perirectal Lymphadenopathy that are hypersignal in T2WI. MRI staging: T3 N1 M0, anterior pelvic resection was done with post-operative pathological staging of T3 N1 M0. Pathological diagnosis; rectal carcinoma "well differentiated adenocarcinoma". 

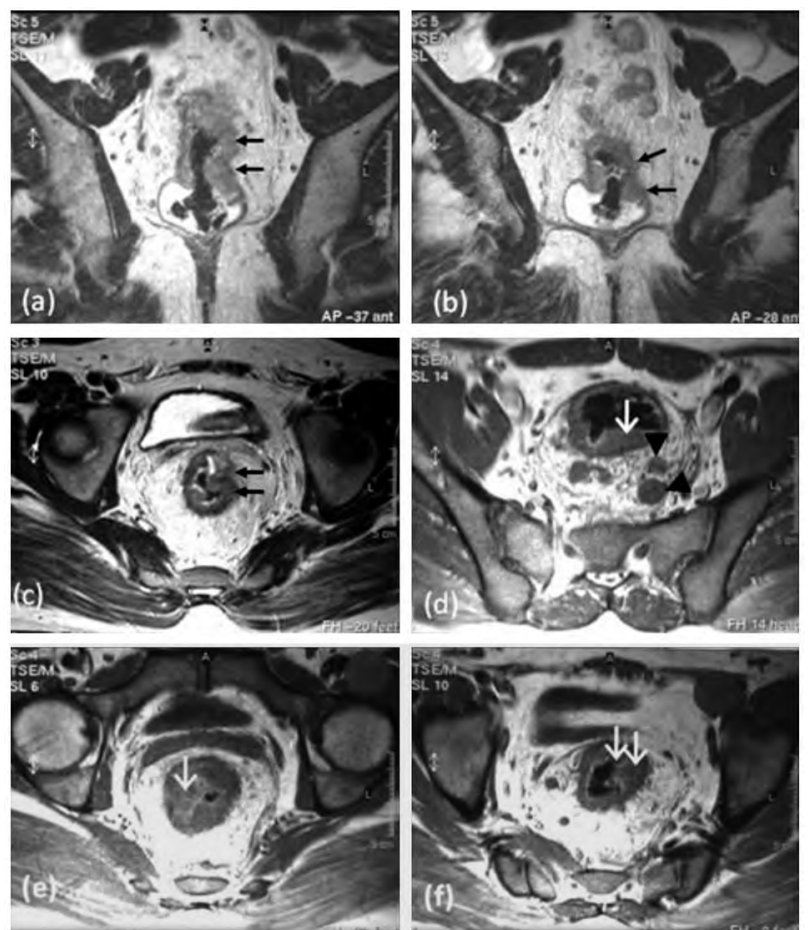

Fig. (3): A-28-year male patient, presented by bleeding per rectum. Pelvic MRI: Coronal T2WI (A \& B), Axial T2WI (C \& D), Axial T1WI (E \& F) showed circumferential rectal wall thickening $6 \mathrm{~cm}$ from the anal verge extending for $6.5 \mathrm{~cm}$, infiltrating all layers of the rectal wall with moderate extension into the perirectal fat. The lesion is iso to hyposignal in T1WI and iso to hypersignal in T2WI No pelvic organs infiltration. Multiple large sized enlarged perirectal LNs are depicted that exhibit iso signal in T1 and T2 WIs. They best have seen in coronal scans. Enlarged nodes at a named vascular trunk are noted (inferior mesenteric vessels). MRI staging: T3 N3 M0, anterior pelvic resection was done after radiation with post-operative pathological staging T3 N3 M0. Pathological diagnosis; rectal carcinoma "Well differentiated Adenocarcinoma".

The sensitivity of MRI was identical to (100\%) operative and histopathological assessment in all $\mathrm{T}$ stages from ( $\mathrm{T} 1$ to $\mathrm{T} 4)$.

\section{$N$ staging:}

The $\mathrm{N}$ stage was interpreted according to the TNM classification, any enlarged node in this study was suspected to be positive for metastatic deposits. The smallest detected LN by MRI was $4 \mathrm{~mm}$, the largest one about $35 \mathrm{~mm}$ in diameter. The nodal signal was isointense in T $1 \mathrm{WI}$, and iso to hyperintense in T2 WI and SPIR. Eighteen cases were staged by MRI as N0, in two of them post-operative histopathological study showed malignant infiltration of perirectal LNs (they were less than $5 \mathrm{~mm}$ in sizes). Four cases were staged as N1, three of them were proved to be positive for metastases in post-operative histopathology and the fourth one was negative. Six cases were staged as N2 and were confirmed in histopathology. The remaining two cases were staged as N3 and were confirmed in histopathology to be positive for malignancy. The overall accuracy of MRI was found to be $90 \%$ (27 from 30). The sensitivity of MRI in assessment of LNs was $75 \%$ for N1 stage, $88.8 \%$ for N0 stage and $100 \%$ for other stages (N2 and N3) in this study.

\section{Operative treatment:}

Amongst the patients of this study 17 patients were treated by abdomino-perineal resection, 8 by anterior pelvic resection and only 5 cases were explored and refused resection. Overall accuracy of MRI in assessment of local infiltration was $100 \%$ and was $90 \%$ (27 correct out of $30 \mathrm{LNs}$ ) in prediction of lymphadenopathy when compared with operative and histopathological findings.

\section{Discussion}

Rectal cancer is associated with a poor prognosis because of the risk both for metastases and for local recurrence. After curative resection of the rectum for rectal cancer, local recurrence rates can vary from $3 \%$ to $32 \%$. Incomplete removal of the lateral spread of the tumor is now accepted as the cause of the majority of these recurrences [10] Therefore, accurate pre-operative staging is essential in establishing an appropriate treatment plan, locally advanced cancers may benefit from neoadjuvant therapy whereas noninvasive or early invasive lesions may be suitable for local resection rather than radical surgery $[\mathbf{5 , 1 1}]$.

For quite a long time, the mainstay of local staging of rectal cancer has been the Digital Rectal Examination (DRE). The accuracy of the digital rectal examination in staging rectal cancer has been accounted to be roughly $70 \%-75 \%$ (in bestexperienced hands) [12], notwithstanding, perirectal adenopathy cannot be detected by this technique [10]. In this study, DRE was performed by an experienced hand in all cases.

In this study the mean age was $43 \pm 3.8$ and the age range was between 19 and 80 years, the mean age was little lower than mean age in a similar study done by Fuchsjäger et al., 2003 (mean age was 49 years) denoting that rectal cancer was dominating in a younger age group in this area [3]

In this study, males were more than females with male to female proportion (2.3:1), while in other study by Fuchsjäger et al., 2003, male to female proportion was $(1.5: 1)$ [3]

Rectal bleeding is a common symptom of colorectal cancer, yet it has a low positive predictive value in primary care populations [13]. In this study, bleeding per rectum was encountered in all cases, denoting that bleeding per rectum is an ominous sign, similar outcomes were found by Fuchsjäger et al., 2003 study [3]. 
Magnetic resonance imaging offers the theoretical advantages over EUS and CT of better tissue discrimination, higher penetration, and less operator reliance. Conventional body coils offer low resolution, whereas endorectal coils share some of the limitations of EUS. The recent introduction of external phase-arrayed coils improved the signalto-noise ratio, permitting high-resolution imaging [14]. This study was designed to determine the role of MRI (using torso body coil) in pre-operative assessment of rectal cancer and the accuracy of both techniques in preoperative staging. This study excluded patients who went through pre-operative radiation therapy because this may confound interpretation of the images.

This study utilized thin cuts axial T2WI with interslice gap zero covering the whole length of tumor routinely in all cases. This matched with all other studies in using axial T1WI \& T2WI as the main stay in staging rectal cancer $[8,15]$.

Coronal and sagittal scans were additionally used to identify the extent of the lesion, distribution of perirectal lymphadenopathy and evaluation of pelvic floor muscles infiltration. MR imaging performed in coronal plane is valuable for distinguishing tumor involvement of the levator ani muscles. This is of therapeutic value as if the levator ani muscles are involved, an anterior resection should not be performed; an abdominoperineal resection is needed [8].

In MRI examination, this study utilized warm water or ordinary saline to distend the rectum in all cases before examination, other studies also favored endorectal filling before MRI examination [16-18]. The water enema technique rationale is that luminal distention of the rectum by water creates a clear distinction between the lumen and the inner wall of the rectum and assists with recognizing the tumor from the fecal material leftover in the rectum. A more noteworthy distention of the outer wall may likewise improve the demarcation between the tumor and the perirectal fat; it additionally replaces any air remaining in the rectum, which may increase a susceptibility artifact during MRI. All patients in the study tolerated this procedure.

Other studies found that it is not obligatory for the utilization of antispasmodic agents but may reduce artifacts brought about by peristalsis when administered immediately preceding the examination [19]. This study did not use antispasmodic agents and no artifacts due to motion could be noted in any of the cases.
This study used IV Gd in just two early cases, then we did not use it due to its cost. It is realized that from other studies that the use of IV Gd does not improve the diagnostic accuracy of local staging of rectal cancer $[\mathbf{1 5 , 2 0 ]}$.

Tumor staging is straightforwardly reliant on the relation of the tumor with the muscularis propria and the invasion of adjacent organs [21]. In this study, the accuracy of MRI in staging T3 was $92 \%$. However other studies revealed that $80 \%$ of rectal tumors are in stage T3 [22]. The overall accuracy was $93.33 \%$, these results were relatively higher than the results of Schnall et al., 1994, who found $\mathrm{T}$ staging accuracy to be $81 \%$ [12]. However, our results were rather like those of Vogl et al., 1997 that were $89 \%$ accuracy [23]. The high accuracy of our $\mathrm{T}$ staging results may be due to the small percent of the early rectal lesions included in this study (i.e., T1 and T2 stages) as the patients presented late in the disease.

The accuracy of MRI in assessment of involvement of metastatic lymph nodes in rectal cancer is less accurate than its accuracy in the tumor staging [24]. The presence of regional lymph node metastasis is reported to be the single most important factor in determining the risk of local tumor recurrence [22].

As a large proportion of metastatic lymph nodes in rectal cancer measure less than $5 \mathrm{~mm}$, size is not a reliable criterion. However, some studies have exhibited that lymph nodes measuring greater than $8 \mathrm{~mm}$ in the short axis are highly specific for metastatic involvement [25,26]. Chan et al., 1991, considered the perirectal lymph node positive for metastasis if visible [27]. This study thought about any enlarged lymph node if seen, to be metastatic.

This study found that the presence or nonappearance of metastatic lymph nodes was correctly predicted in $90 \%$ of cases. This was relatively higher than, Blomqvist et al., 1997 who found that the overall accuracy of MRI in determining the presence of metastatic perirectal lymph nodes $78 \%$ [28]. Sensitivity for perirectal lymph node involvement in this study was $75 \%$ for $\mathrm{N} 1$ and $88.8 \%$ for No.

If muscle, nerve, or bony involvement is suspected or if extensive and invasive disease is expected, MR imaging is of choice because of ease with which this technique can assess tumor extension into these structures. MR imaging can evaluate the various soft tissue components of many pelvic organs and can more readily distinguish soft tissue planes between pelvic organs and masses [8] 
Previous studies found that $30-50 \%$ of patients having pelvic organ infiltration at time of diagnosis would develop local tumoral recurrence in 5 years interval [29]. So appropriate assessment of the pelvic organ infiltration has become necessary, as certain studies have indicated that pre-operative irradiation gives better survival rates than doe's post-operative radiation therapy [8]

Almost half of the patients with recurrence of rectal cancer have disease that is confined to the pelvis and can be considered technically resectable. For these patients, it is presently settled that radical surgery offers the best chance of long-term survival [29].

\section{Conclusions:}

Pelvic MRI provides high resolution images of the entire mesorectum allowing for an accurate staging of rectal cancer. It offers multiplanar abilities with high resolution, non-invasive however, it is relatively a costly examination. It is of high value in establishing the best therapy methodology for cancer rectum patients.

\section{Conflicts of interest:}

There are no conflicts of interest.

\section{References}

1- FERLAY J., SOERJOMATARAM I., DIKSHIT R., ESER S., MATHERS C., REBELO M., et al.: Cancer incidence and mortality worldwide: Sources, methods and major patterns in GLOBOCAN 2012. International journal of cancer, 136 (5): E359-86, 2015.

2- BAILEY C.E., HU C.Y., YOU Y.N., BEDNARSKI B.K., RODRIGUEZ-BIGAS M.A., SKIBBER J.M., et al.: Increasing disparities in the age-related incidences of colon and rectal cancers in the United States, 1975-2010. JAMA surgery, 150 (1): 17-22, 2015.

3- FUCHSJ ÄGER M.H., MAIER A.G., SCHIMA W., ZEBEDIN E., HERBST F., MITTLBÖCK M., et al.: Comparison of transrectal sonography and double-contrast MR imaging when staging rectal cancer. AJR American journal of roentgenology, 181 (2): 421-7, 2003.

4- VLIEGEN R.F., BEETS G.L., VON MEYENFELDT M.F., KESSELS A.G., LEMAIRE E.E., VAN ENGELSHOVEN J.M., et al.: Rectal cancer: MR imaging in local staging--is gadolinium-based contrast material helpful? Radiology, 234 (1): 179-88, 2005.

5- ARYA S., DAS D., ENGINEER R. and SAKLANI A.: Imaging in rectal cancer with emphasis on local staging with MRI. Indian J. Radiol. Imaging, 25 (2): 148-61, 2015.

6- WIGGERS T. and VAN De VELDE C.J.: The circumferential margin in rectal cancer. Recommendations based on the Dutch Total Mesorectal Excision Study. European journal of cancer (Oxford, England : 1990), 38 (7): 973 6, 2002.
7- PATEL U.B., TAYLOR F., BLOMQVIST L., GEORGE C., EVANS H., TEKKIS P., et al.: Magnetic resonance imaging-detected tumor response for locally advanced rectal cancer predicts survival outcomes: MERCURY experience. Journal of clinical oncology: Official Journal of the American Society of Clinical Oncology, 29 (28): 3753-60, 2011.

8- HORVAT N., ROCHA C.C.T., OLIVEIRA B.C., PETKOVSKA I. and GOLLUB M.J.: MRI of Rectal Cancer: Tumor Staging, Imaging Techniques, and Management, 39 (2): 367-87, 2019.

9- KUMAR A. and SCHOLEFIELD J.H.: Endosonography of the anal canal and rectum. World journal of surgery, 24 (2): 208-15, 2000.

10- BEETS-TAN R.G. and BEETS G.L.: Rectal cancer: Review with emphasis on MR imaging. Radiology, 232 (2): 335-46, 2004.

11- ZAMMIT M., JENKINS J.T., URIE A., O'DWYER P.J. and MOLLOY R.G.: A technically difficult endorectal ultrasound is more likely to be inaccurate, 7 (5): 486-91, 2005.

12- SCHNALL M.D., FURTH E.E., ROSATO E.F. and KRESSEL H.Y.: Rectal tumor stage: Correlation of endorectal MR imaging and pathologic findings. Radiology, 190 (3): 709-14, 1994

13- ROBERTSON R., CAMPBELL C., WELLER D.P., ELTON R., MANT D., PRIMROSE J., et al.: Predicting colorectal cancer risk in patients with rectal bleeding. Br. J. Gen. Pract., 56 (531): 763-7, 2006.

14- TAPAN U., OZBAYRAK M. and TATL1 S.: MRI in local staging of rectal cancer: An update. Diagn. Interv. Radiol., 20 (5): 390-8, 2014.

15-BROWN G., RICHARDS C.J., NEWCOMBE R.G., DALLIMORE N.S., RADCLIFFE A.G., CAREY D.P., et al.: Rectal carcinoma: Thin-section MR imaging for staging in 28 patients. Radiology, 211 (1): 215-22, 1999.

16- KIM J.H., BEETS G.L., KIM M.J., KESSELS A.G. and BEETS-TAN R.G.: High-resolution MR imaging for nodal staging in rectal cancer: Are there any criteria in addition to the size? European journal of radiology, 52 (1): 78-83, 2004.

17- GOLLUB M.J., ARYA S., BEETS-TAN R.G., DePRISCO G., GONEN M., JHAVERI K., et al.: Use of magnetic resonance imaging in rectal cancer patients: Society of Abdominal Radiology (SAR) rectal cancer disease-focused panel (DFP) recommendations 2017. Abdominal radiology (New York), 43 (11): 2893-902, 2018.

18- YE F., ZHANG H., LIANG X., OUYANG H., ZHAO X. and ZHOU C.: Journal Club: Preoperative MRI Evaluation of Primary Rectal Cancer: Intrasubject Comparison With and Without Rectal Distention. AJR American journal of roentgenology, 207 (1): 32-9, 2016.

19- BEETS-TAN R.G.H., LAMBREGTS D.M.J., MAAS M., BIPAT S., BARBARO B., CURVO-SEMEDO L., et al.: Magnetic resonance imaging for clinical management of rectal cancer: Updated recommendations from the 2016 European Society of Gastrointestinal and Abdominal Radiology (ESGAR) consensus meeting. European radiology, 28 (4): 1465-75, 2018. 
20- TAYLOR F.G., SWIFT R.I., BLOMQVIST L. and BROWN G.: A systematic approach to the interpretation of pre-operative staging MRI for rectal cancer. AJR American journal of roentgenology, 191 (6): 1827-35, 2008.

21- KAUR H., CHOI H., YOU Y.N., RAUCH G.M., JENSEN C.T., HOU P., et al.: MR imaging for pre-operative evaluation of primary rectal cancer: Practical considerations. Radiographics: A review publication of the Radiological Society of North America, Inc., 32 (2): 389-409, 2012.

22- ALUJA JARAMILLO F. and UPEGUI JIMÉNEZ D.: Estadificación del cáncer colorrectal mediante resonancia magnética \% J. Revista Colombiana de Gastroenterologia, 31: 273-82, 2016.

23- VOGL T.J., PEGIOS W., MACK M.G., HÜNERBEIN M., HINTZE R., ADLER A., et al.: Accuracy of staging rectal tumors with contrast-enhanced transrectal MR imaging. AJR American Journal of Roentgenology, 168 (6): 1427-34, 1997

24- AL-SUKHNI E., MILOT L., FRUITMAN M., BEYENE J., VICTOR J.C., SCHMOCKER S., et al.: Diagnostic accuracy of MRI for assessment of T category, lymph node metastases, and circumferential resection margin involvement in patients with rectal cancer: A systematic review and meta-analysis. Annals of Surgical Oncology, 19 (7): 2212-23, 2012.

25- BEETS-TAN R.G.: Pretreatment MRI of lymph nodes in rectal cancer: An opinion-based review. Colorectal disease: The official journal of the Association of Coloproctology of Great Britain and Ireland, 15 (7): 781-4, 2013.

26- BEETS-TAN R.G.H., LAMBREGTS D.M.J., MAAS M., BIPAT S., BARBARO B., CURVO-SEMEDO L., et al.: Magnetic resonance imaging for clinical management of rectal cancer: Updated recommendations from the 2016 European Society of Gastrointestinal and Abdominal Radiology (ESGAR) consensus meeting. European Radiology, 28 (4): 1465-75, 2018.

27- CHAN T.W., KRESSEL H.Y., MILESTONE B., TOMACHEFSKI J., SCHNALL M., ROSATO E., et al.: Rectal carcinoma: Staging at MR imaging with endorectal surface coil. Work in progress. Radiology, 181 (2): 461-7, 1991.

28- BLOMQVIST L., HOLM T., RUBIO C. and HINDMARSH T.: Rectal tumours - MR imaging with endorectal and/or phased-array coils, and histopathological staging on giant sections. Acta Radiologica, 38 (3): 437-44, 1997.

29- MIRNEZAMI A.H. and SAGAR P.M.: Surgery for recurrent rectal cancer: Technical notes and management of complications. Techniques in Coloproctology, 14 (3): 209-16, 2010

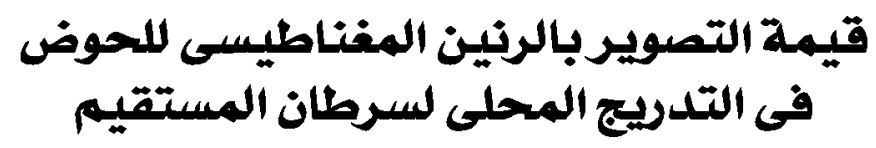

$$
\begin{aligned}
& \text { الآهداف: هدفت هذه الدراسة إلى تقييم دور التصوير بالرنين المغناطيسى الحوض فى تصديد مراحل سرطان المستقيم لتقرير العلاج. } \\
& \text { المرضى والطرق: تضمنت هذه الدراسة الإستطلاعية ـ. مريضاً ثبت إصابتهم بسرطان المستقيم من خلال الدراسات السريرية والمرضية. }
\end{aligned}
$$

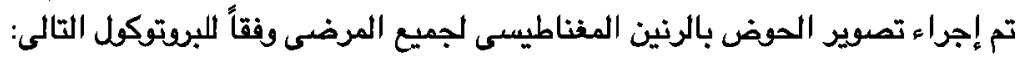

T T والتدريج N T للآفات. Sagittal T2WI; Axial T2WI; Axial T1SPIR; Axial T1WI; and Coronal T2 TSE

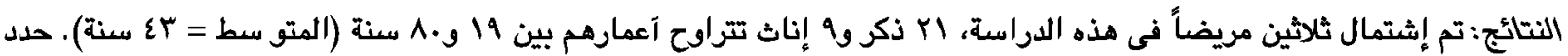

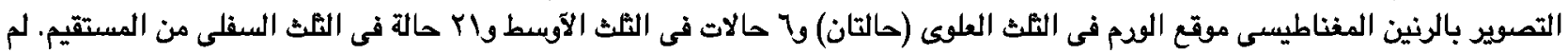

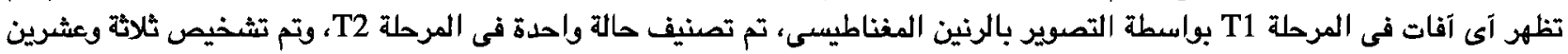

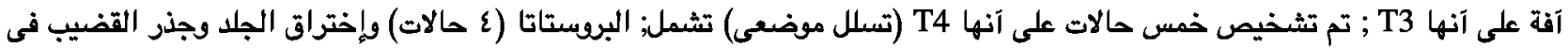

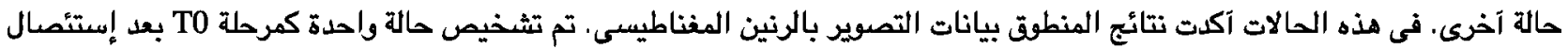

الإستتاجات: يوفر التصوير بالرنين المغناطيسى للحوض صوداً عالية الدقة للمستقيم (mesorectum) باكمله مما يسمع بالتدريج الدقيق

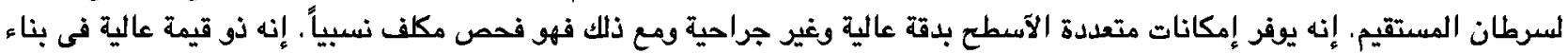
آفضل إستراتيجية علاجية لمرضى سرطان المشئ المستقيم. 